\title{
Sequence-dependent synergism and antagonism between paclitaxel and gemcitabine in breast cancer cells: The importance of scheduling
}

\author{
CRISTINA OLIVERAS-FERRAROS ${ }^{1,2}$, ALEJANDRO VAZQUEZ-MARTIN ${ }^{1,2}$, RAMON COLOMER ${ }^{1,2,3}$, \\ RAFAEL DE LLORENS $^{4}$, JOAN BRUNET ${ }^{1,2}$ and JAVIER A. MENENDEZ ${ }^{1,2}$ \\ ${ }^{1}$ Metabolism and Cancer Laboratory, Girona Biomedical Research Institute (IdIBGi), Dr Josep Trueta University \\ Hospital of Girona; ${ }^{2}$ Catalan Institute of Oncology (ICO)-Health Services Division of Catalonia; \\ ${ }^{3}$ M.D. Anderson International Madrid, Madrid; ${ }^{4}$ Biochemistry and Molecular Biology of Cancer, \\ Faculty of Sciences, University of Girona (UdG), Girona, Catalonia, Spain
}

Received May 29, 2007; Accepted August 12, 2007

\begin{abstract}
The marked clinical anticancer activity of the paclitaxel (PTX) and gemcitabine (GEM) combination has suggested that the two drugs may interact more than additively. We have analyzed the in vitro growth and molecular interactions of the two chemotherapy drugs in a panel of human breast cancer cells. We evaluated cell viability in four breast cancer cell lines (i.e., MCF-7, MDA-MB-231, MDA-MB468, and SKBR3) that were treated with PTX and GEM combined either simultaneously (PTX + GEM) or sequentially $(\mathrm{PTX} \rightarrow \mathrm{GEM}$; GEM $\rightarrow$ PTX). PTX-GEM interactions at the cellular level were assessed mathematically employing both the isobologram analysis (Berenbaum) and the combination index (Chou-Talalay) method. PTX-GEM molecular interactions on the apoptotic markers PARP, Bcl-2 and Bax were analyzed by immunoblotting procedures. Apoptosis was detected using a DNA ladder assay. We observed significant synergistic growth inhibitory interactions when PTX was administered before GEM. Additive interactions were observed when both the simultaneous regimen and the GEM followed by PTX regimen were used. DNA ladder and Western blotting results in the PTX followed by GEM sequence revealed a significant increase in the apoptotic cell death of breast cancer cells related to the Bax/Bcl-2 apoptotic pathway. In summary, the occurrence of clinically relevant synergism between PTX and GEM suggests a sequence-dependent nature in human breast cancer cells. This synergistic interaction on the PTX $\rightarrow$ GEM schedule appears to be related to an increase
\end{abstract}

Correspondence to: Dr Javier A. Menendez, Metabolism and Cancer Laboratory, Girona Biomedical Research Institute (IdIBGi), Dr Josep Trueta University Hospital of Girona, Avenida de Francia s/n; 17007 Girona, Catalonia, Spain

E-mail: jmenendez@ico.scs.es

Key words: paclitaxel, gemcitabine, chemotherapy, breast cancer, Bcl-2 in the Bcl-2-related mitochondrial apoptotic pathway. The synergism that we have observed may explain the favorable clinical responses that have been achieved in clinical studies, in which patients are administered PTX first, and then GEM.

\section{Introduction}

Paclitaxel (PTX) is a member of the taxane family isolated from the Pacific yew (Taxus brevifolia) (1), known to inhibit cancer cell growth and trigger apoptosis. PTX is a microtubuleinterfering agent, which causes the stabilisation of the mitotic spindle microtubules through the binding to the $\beta$-tubulin subunit leading to cell cycle arrest in the $G_{2} / M$ phase of the cell cycle, and apoptosis $(2,3)$. It is used in the treatment of women with advanced breast cancer, with response rates ranging from $31 \%$ to $50 \%(4,5)$, and it is also used in the treatment of other cancers including ovarian and lung $(6,7)$.

Gemcitabine (2'-2'-difluorodeoxycytidine; dFdCyd; GEM) is a nucleoside analogue used in solid tumor therapy, such as that of non-small cell lung, ovarian, pancreas and breast cancer (8). GEM is incorporated mainly within replicating DNA and leads to termination of DNA chain elongation. It also inhibits DNA synthesis through inhibition of DNA polymerases leading to cell cycle arrest in the $\mathrm{G}_{1} / \mathrm{S}$ phase of the cell cycle, which causes apoptosis. GEM toxicity can be increased on inhibition of the ribonucleotide reductase, which blocks de novo deoxyribonucleotide synthesis $(9,10)$. As a single agent, GEM yields response rates ranging from 14 to $37 \%$ as a first-line treatment for advanced breast cancer $(11,12)$ and $16-29 \%$ as a salvage therapy for patients previously treated with chemotherapy $(13,14)$.

Combination chemotherapy offers the possibility of enhanced antitumor efficacy. Criteria for an effective combination include the use of drugs with different mechanisms of action, relative non-cross-resistance, and partially non-overlapping toxicities. PTX and GEM fulfil these criteria because PTX acts against microtubules inducing cell cycle arrest in the $\mathrm{G}_{2} / \mathrm{M}$ phase and GEM acts against DNA and causes cell cycle arrest in the $G_{1} / S$ phase, and they have 
non-overlapping toxicities. Excellent responses are achieved in experimental studies of this combination (15-18), but there is limited experience regarding which is the more appropriate sequence of administration. In this study we have evaluated the cellular and molecular interactions between PTX and GEM in cultured human breast cancer cells. In addition, we have investigated whether there is a more active treatment schedule.

\section{Materials and methods}

Cell culture. The human breast cancer cell lines MCF-7, MDA-MB-231, MDA-MB-468 and SKBR3 were obtained from the American Type Culture Collection (ATCC), and were maintained in a humidified atmosphere containing $5 \%(\mathrm{v} / \mathrm{v})$ $\mathrm{CO}_{2}$ at $37^{\circ} \mathrm{C}$. All the breast cancer cell lines were cultured in DMEM medium (Gibco), with the exception of the SKBR3 cell line that was cultured in McCoy's medium (Gibco). DMEM and McCoy media were supplemented with $10 \%$ synthetic foetal bovine serum (HyClone), 1\% L-Glutamine (Biochrom AG), 1\% sodium pyruvate (Biochrom AG) and $1 \%$ penicillin-streptomycin (Gibco), and routinely sub-cultured twice weekly, detaching them using trypsin $1 \mathrm{X}$ in PBS (Gibco). Trypsin activity was stopped using fresh culture medium.

Cytotoxicity assay. Cells (7x103/well in the two-drug combination) in their exponential cell growth were plated in 96-well microdilution plates (Corning). Following cell adherence $(24 \mathrm{~h})$, experimental medium containing the chemotherapeutic drug(s) was added to triplicate wells (PTX, Bristol-Myers Squibb; GEM, Eli Lilly), and serial dilutions were performed to span the dose range suitable for isobologramic analysis (Table I). We analysed the three possible schedules for the two-drug combination: PTX plus GEM (simultaneous), PTX followed by GEM and GEM followed by PTX. In all cases, time exposure to cytotoxic drugs was $72 \mathrm{~h}$. For the sequential treatments, the first drug was used for $24 \mathrm{~h}$, and the second for the following $48 \mathrm{~h}$. The doses used to study drug combination were close to $\mathrm{IC}_{30}$ values.

Following treatment, a cell viability assay was performed using the MTT (3-4,5-dimethylthiazol-2-yl-2,5-diphenyltetrazolium bromide) method (19). Some changes on the protocol described by Mosmann were performed. Briefly, the medium was removed and replaced by fresh drug-free medium (100 $\mu \mathrm{l} / \mathrm{well})$, and MTT (5 $\mathrm{mg} / \mathrm{ml}$ in PBS) was added to each well at a $1 / 10$ volume. After incubation for $2-3 \mathrm{~h}$ at $37^{\circ} \mathrm{C}$, the supernatants were carefully aspirated, $100 \mu \mathrm{l}$ of DMSO was added to each well, and the plates were agitated to dissolve the crystal product. Absorbances were measured at $570 \mathrm{~nm}$ using a multi-well plate reader (Model Anthos Labtec 20101.7 reader). The cell viability effects from exposure of cells to each compound alone and their combination were analyzed as percentages of the control cell absorbances, which were obtained from control wells treated with appropriate concentrations of the compounds' vehicles that were processed simultaneously. For each treatment, cell viability was evaluated as a percentage using the following equation: (A570 of treated sample/A570 of untreated sample) x100.

Synergy analysis: Berenbaum's isobologram and Chou-Talalay (median-effect plot) method. This dose-oriented mathematical
Table I. Dose range suitable for the drug-combination analyses in each cell line.

\begin{tabular}{lcc}
\hline Cell line & PTX $(\mathrm{ng} / \mathrm{ml})$ & GEM $(\mathrm{ng} / \mathrm{ml})$ \\
\hline SKBR3 & $0.1-10$ & $1-25$ \\
MCF-7 & $0.1-10$ & $50-1000$ \\
MDA-MB-231 & $0.1-25$ & $50-1000$ \\
MDA-MB-468 & $0.1-10$ & $1-100$ \\
\hline
\end{tabular}

method to assess the nature of the interaction between therapeutic agents requires the determination of a given biological effect when the concentration ratio of two agents varies (20). In our experiments, the $\mathrm{IC}_{30}$ value (i.e., the drug concentration needed to cause $30 \%$ reduction in cell viability) was chosen for comparisons. An interaction index $\left(\mathrm{I}_{\mathrm{x}}\right)$ was calculated using the following equation $\mathrm{I}_{\mathrm{x}}=\sum \mathrm{E}(\mathrm{y})=\sum\left(\mathrm{d}_{\mathrm{x}} / \mathrm{D}_{\mathrm{x}}\right)$ where $\mathrm{d}_{\mathrm{x}}$ is the dose needed to cause $\mathrm{x} \%$ of growth inhibition when the drug is combined with another, and $D_{x}$ is the dose needed to cause the same effect when the drug is administered alone. Isoboles were constructed by plotting $\mathrm{E}(\mathrm{PTX})=\mathrm{d}_{\mathrm{x}} / \mathrm{D}_{\mathrm{x}}$ of PTX versus $\mathrm{E}(\mathrm{GEM})=\mathrm{d}_{\mathrm{x}} / \mathrm{D}_{\mathrm{x}}$ of GEM. If data points fall to the left of the additivity line $\left(I_{x}<1\right)$, synergy is indicated; if the data fall within the additivity line $\left(I_{x}=1\right)$, drug interaction is said to be additive; if the data points fall to the right of the additivity line $\left(I_{x}>1\right)$ then the combination is considered antagonistic.

Synergism, additivity or antagonism of the drugs was also determined by the median effect analysis (21). This involves plotting dose-effect curves for each agent and for multiply diluted, fixed ratio combinations of agents using the medianeffect equation $(a): \mathrm{f}_{\mathrm{a}} / \mathrm{f}_{\mathrm{u}}=\left(\mathrm{D} / \mathrm{D}_{\mathrm{m}}\right)^{\mathrm{m}}$. In this equation, $\mathrm{D}$ is dose, $\mathrm{D}_{\mathrm{m}}$ is the dose required for $50 \%$ effect (e.g., $50 \%$ inhibition of cell growth, $\left.\mathrm{ED}_{50}\right), \mathrm{f}_{\mathrm{a}}$ is the fraction affected by dose $\mathrm{D}$ (e.g., 0.9 if cell growth is inhibited by $90 \%), \mathrm{f}_{\mathrm{u}}$ is the unaffected fraction (therefore, $f_{u}=1-f_{a}$ ), and $m$ is a coefficient of sigmoidicity of the dose-effect curve; $m=1,>1$, and $<1$ indicate hyperbolic, sigmoid and negative sigmoid dose-effect curves, respectively, for an inhibitory drug.

Equation $a$ may be rearranged as follows $(b)$ : $\mathrm{D}_{\mathrm{x}}=$ $D_{m}\left[f_{a} /\left(1-f_{a}\right)\right]^{1 / m}$. The parameters $m$ and $D_{m}$ are easily determined by the median-effect plot $\mathrm{x}=\log (\mathrm{D})$ versus $\mathrm{y}=\log \left[\mathrm{f}_{\mathrm{a}} /\left(1-\mathrm{f}_{\mathrm{a}}\right)\right]$, which is based on the logarithmic form of equation $a$ and yield a straight line where $\mathrm{m}$ is the slope and $\log \left(\mathrm{D}_{\mathrm{m}}\right)$ is the $\mathrm{x}$ intercept. $\mathrm{IC}_{50}$ values (by interpolation) and $\mathrm{D}_{\mathrm{m}}$ values (by the median-effect plot) were usually similar. Equation $b$ may thus be solved, providing the iso-effective dose $\left(\mathrm{D}_{\mathrm{x}}\right)$ for any effect level (e.g. $\mathrm{ED}_{80}$ for $\mathrm{f}_{\mathrm{a}}=0.8 ; \mathrm{ED}_{90}$ for $\mathrm{f}_{\mathrm{a}}=0.9$, and so forth). $\mathrm{A}$ combination index $(\mathrm{CI})$ is then determined with the following equation $(c)$ : $C I=(D)_{1} /\left(D_{x}\right)_{1}+(D)_{2} /\left(D_{x}\right)_{2}+\alpha(D)_{1}(D)_{2} /\left(D_{x}\right)_{1}\left(D_{x}\right)_{2}$ where $\left(D_{x}\right)_{1}$ is the dose of agent 1 required to produce $x$ percent effect alone, and (D) $)_{1}$ is the dose of agent 1 required to produce the same $\mathrm{x}$ percent effect in combination with (D) $)_{2}$. Similarly $\left(D_{x}\right)_{2}$ is the dose of agent 2 required to produce $\mathrm{x}$ percent effect alone, and (D) ${ }_{2}$ is the dose required to produce the same effect in combination with $(\mathrm{D})_{1}$. If the agents are 
Table II. Single drug $\mathrm{IC}_{30}$ values upon different PTX/GEM combination schedules.

\begin{tabular}{lccccccc}
\hline Cell line & \multicolumn{3}{c}{ PTX $(\mathrm{ng} / \mathrm{ml})$} & & \multicolumn{3}{c}{ GEM $(\mathrm{ng} / \mathrm{ml})$} \\
\cline { 2 - 3 } \cline { 7 - 8 } & $\mathrm{A}$ & $\mathrm{B}$ & $\mathrm{C}$ & & $\mathrm{A}$ & $\mathrm{B}$ & $\mathrm{C}$ \\
\hline SKBR3 & $1.4 \pm 0.6$ & $1.9 \pm 1$ & $2.8 \pm 1.2$ & & $5.1 \pm 1.6$ & $6.9 \pm 2.1$ & $13.81 \pm 2.6$ \\
MCF-7 & $2.8 \pm 1.1$ & $2.7 \pm 0.3$ & $10.1 \pm 2.1$ & & $116 \pm 33.8$ & $206.2 \pm 53.7$ & $223.8 \pm 65.1$ \\
MDA-MB-231 & $3.6 \pm 0.6$ & $9.7 \pm 5.7$ & $18.59 \pm 3.8$ & & $70.1 \pm 14.6$ & $137.3 \pm 66.6$ & $351.1 \pm 73.3$ \\
MDA-MB-468 & $0.4 \pm 0.06$ & $0.7 \pm 0.05$ & $1.8 \pm 0.2$ & & $38.6 \pm 15$ & $15.3 \pm 0.7$ & $62.07 \pm 8$ \\
\hline
\end{tabular}

A, 72-h drug treatment; B, drug for $24 \mathrm{~h} \rightarrow$ drug-free medium for $48 \mathrm{~h}$; C, drug-free medium for $48 \mathrm{~h} \rightarrow$ drug for $24 \mathrm{~h}$.

mutually exclusive (e.g., similar mode of action), then $\alpha$ is 0 (i.e., $\mathrm{CI}$ is the sum of 2 terms); if the agents are mutually non-exclusive (e.g., independent mode of action), $\alpha$ is 1 (i.e., $\mathrm{CI}$ is the sum of 3 terms). If it is uncertain whether the agents act in a similar or an independent manner, the formula may be solved both ways. Different values of CI may be obtained by solving the equation for different values of $\mathrm{f}_{\mathrm{a}}$ (e.g., different degrees of inhibition of cell growth). CI values of $<1$ indicate synergy (the smaller the value, the greater the degree of synergy), values $>1$ indicate antagonism and values equal to 1 indicate additive effects. In our current studies, CI profiles were compared to a preset null interval of 0.95-1.05 (addition), so that mean CI values $>1.05$ or $<0.95$ were interpreted as being suggestive of antagonism and synergism, respectively. Each experiment was carried out with triplicate cultures for each data and was repeated independently at least three times. The conformity of the experimental data to the median-effect principle of the mass-action law was automatically provided by the computer printout in terms of the linear correlation coefficient (r-value) of the median-effect plots. In our studies, the r-values for PTX, GEM and their combinations were all $>0.95$.

Immunoblotting. Cells $\left(\sim 6 \times 10^{5}\right)$ were seeded in $100-\mathrm{mm}$ Petri dish plates (Corning). Following cell adherence $(24 \mathrm{~h}$ ), cells were treated with drugs in the different schedules described previously. Following treatment, cells were washed in PBS and lysed with lysis buffer (Tris $50 \mathrm{mM} \mathrm{pH} \mathrm{7.5,} \mathrm{NaCl} 150 \mathrm{mM}$, EDTA $1 \mathrm{mM}$, Ortovanadate-Na $0.02 \mathrm{mM}, 1 \%$ Triton X-100, PMSF $0.5 \mathrm{mM}$ and protease cocktail). The quantification of the total protein was made by a Lowry assay (BioRad). Clarified protein lysates (30 to $50 \mu \mathrm{g}$ of protein of each sample) were electrophoretically resolved on 4-12\% MOPS NuPage gels (Invitrogen), transferred to a $0.45-\mu \mathrm{m}$ pore size nitrocellulose membrane (Invitrogen), and then proved with anti-PARP (Oncogene), anti-Bax (Neomarkers), anti-Bcl-2 (Neomarkers), and anti- $\beta$-actin (Santa Cruz Biotechnology) antibodies. Proteins were detected using peroxidase-conjugated anti-mouse or anti-rabbit immunoglobulines (Calbiochem) followed by incubation with Super-Signal West Pico chemiluminescence substrate (Pierce).

DNA ladder. Apoptosis was detected using the Suicide track DNA ladder kit (Calbiochem). Following treatments, DNA was extracted as per the manufacturer's instructions, and equal amounts of DNA were electrophorated through a 1.5\% agarose gel containing $0.3 \mu \mathrm{g} / \mathrm{ml}$ ethidium bromide. Bands were visualized under UV Transilluminator Syngene (Bio Imaging Systems).

Statistical analysis. All experiments were performed in triplicate and were repeated at least three times. Data were expressed as mean values $\pm \mathrm{SD}$, and were analysed by Student's $\mathrm{t}$-test; the level of significance was set at $\mathrm{p}<0.05$.

\section{Results}

Single-agent activity. When MCF-7, MDA-MB-231, MDAMB-468, and SKBR3 human breast carcinoma cell lines were treated with graded concentrations of single-drug PTX or GEM, we observed a dose-dependent decrease in the percentage of cell viability. The $\mathrm{IC}_{30}$ values (i.e., the concentrations of the drugs needed to reduce cell viability by $30 \%$ ) ranged from 0.4 to $18.6 \mathrm{ng} / \mathrm{ml}$ in the case of PTX, and from 5 to $350 \mathrm{ng} / \mathrm{ml}$ in the case of GEM (Table II). The highly-metastatic MDAMB-231 cell line was significantly more resistant to the tumoricidal effects of PTX and GEM when compared to MCF-7, SKBR3 and MDA-MB-468.

Synergy analyses. To evaluate potential synergistic or antagonistic interactions between PTX and GEM, we first performed combination studies at a non-fixed molar ratio by the isobologram method using drug-concentrations close to PTX and $\mathrm{GEM} \mathrm{IC}_{30}$ values.

I. Simultaneous schedule $(P T X+G E M)$. Both the interaction indexes $\left(\mathrm{I}_{30} \approx 1\right.$; Table III) and the isobolograms (Fig. 1a) revealed additive interactions when PTX and GEM were used concomitantly in SKBR3, MCF-7 and MDA-MB-468 breast cancer cell lines. An antagonistic interaction was apparent in MDA-MB-231 cells.

II. Sequential schedule $(P T X \rightarrow G E M ; G E M \rightarrow P T X)$. A different picture emerged upon sequential administration of PTX and GEM. When PTX was administered prior to GEM (Fig. 1b; Table III) a statistically significant synergy was observed in SKBR3, MCF-7 and MDA-MB-231 cell lines $\left(\mathrm{I}_{30}<1\right)$, while additive interactions occurred in MDA-MB-468 cells. When the drugs were administered in the sequence GEM followed by PTX, no synergism was observed (Fig. 1c; Table III). 
Table III. Interaction index $\left(\mathrm{I}_{\mathrm{x}}\right)$ values for the combination of PTX/GEM Gemcitabine at $30 \%$ of cell death.

\begin{tabular}{|c|c|c|c|c|c|c|}
\hline \multirow[b]{2}{*}{ Cell line } & \multicolumn{2}{|c|}{ PTX $\rightarrow$ GEM } & \multicolumn{2}{|c|}{$\mathrm{GEM} \rightarrow \mathrm{PTX}$} & \multicolumn{2}{|c|}{ PTX + GEM } \\
\hline & $\mathrm{I}_{30}$ & Result & $\mathrm{I}_{30}$ & Result & $\mathrm{I}_{30}$ & Result \\
\hline SK-Br3 & $0.862^{\mathrm{a}} \pm 0.47$ & Synergy & $1.252 \pm 0.36$ & Addition & $0.965 \pm 0.41$ & Addition \\
\hline MCF-7 & $0.672^{\mathrm{a}} \pm 0.26$ & Synergy & $0.984 \pm 0.38$ & Addition & $1.303 \pm 0.67$ & Addition \\
\hline MDA-MB-231 & $0.889^{\mathrm{a}} \pm 0.10$ & Synergy & $1.05 \pm 0.41$ & Addition & $3.244^{\mathrm{a}} \pm 1.17$ & Antagonism \\
\hline MDA-MB-468 & $1.137 \pm 0.26$ & Addition & $1.238^{\mathrm{a}} \pm 0.03$ & Antagonism & $1.05 \pm 0.44$ & Addition \\
\hline
\end{tabular}

${ }^{\mathrm{a}}$ Significance $(\mathrm{p}<0.05)$.

a

\section{PTX + GEM}
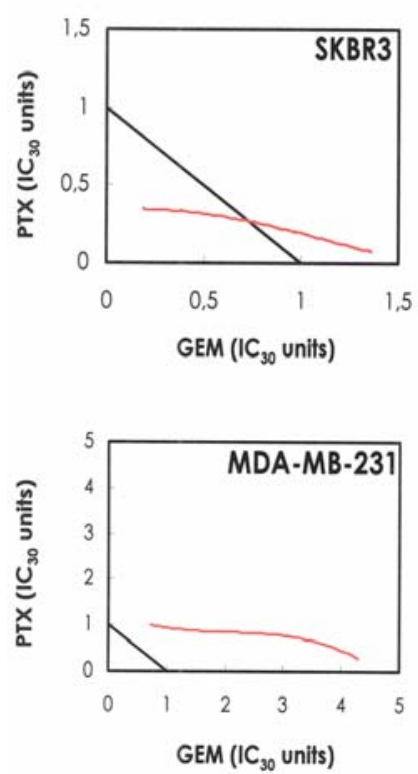
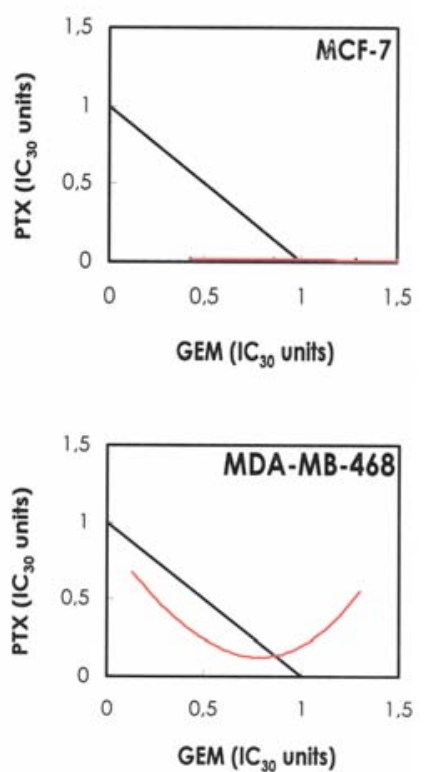

Figure 1. Synergy analyses of the interaction between PTX and GEM in human breast carcinoma cells. The nature of the interaction between PTX and GEM upon three different schedules (a, PTX + GEM; b, PTX $\rightarrow$ GEM, and $\mathrm{c}, \mathrm{GEM} \rightarrow \mathrm{PTX}$ ) was evaluated by the isobologram technique, a doseoriented geometric method of assessing drug interactions. Upon this approach, the concentration of GEM producing a desired (e.g., 30\% inhibitory) effect was plotted on the horizontal axis, and the concentration of PTX producing the same cytostatic degree was plotted on the vertical axis; a straight line joining these two points represents zero interaction between the two agents $\left(\mathrm{I}_{30}=1.0\right.$, addition). An experimental isoeffect point is the concentration (expressed relative to GEM and PTX $\mathrm{IC}_{30}$ concentrations) of the two agents which when combined reduced cell viability by either $30 \%$. Within the designed assay range, a set of isoeffect points was generated because there were multiple GEM and PTX concentrations that achieved the same isoeffect. In our present study, the mean values of the survival fractions were used to generate the set of experimental isoeffect points and construct the isobole for a given PTX-GEM combination. Data points above the diagonal line of the additive effects in the isobole suggest antagonism and those below the diagonal suggest synergism. Isobologram analysis was assessed only when obtained directly from actual experiments.

In order to confirm the synergistic interaction occurring when administered sequentially (i.e., PTX $\rightarrow$ GEM), the combined cytotoxic effect of PTX and GEM was further assessed using the (fixed molar ratio) median-effect plot analysis of Chou et al (21). This procedure allows the b $\quad$ PTX $\rightarrow$ GEM
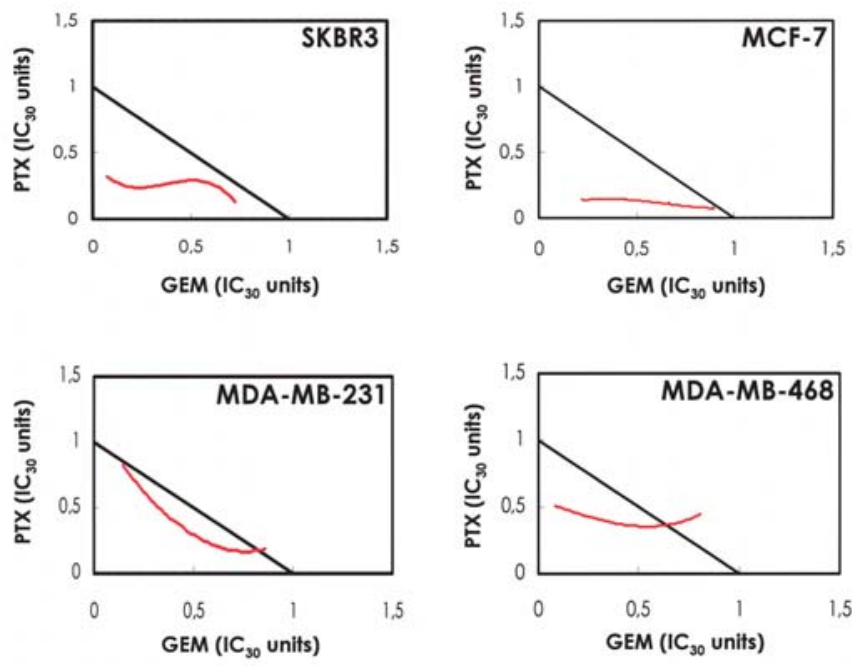

C $\quad$ GEM $\rightarrow$ PTX
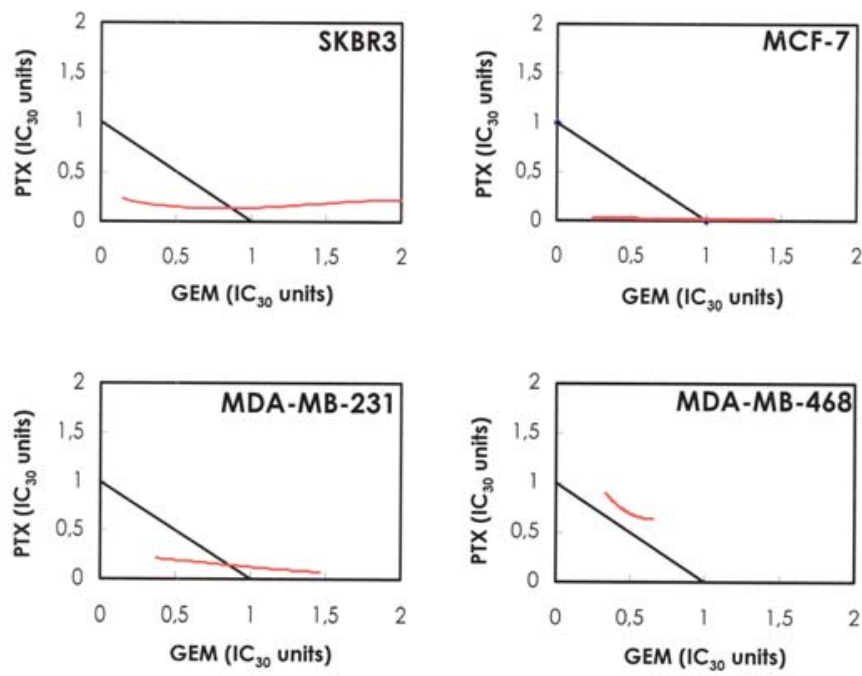

characterization of drug interactions with a single number, the Combination Index (CI). The CI parameter indicates whether the doses of the two agents required to produce a given degree of cytotoxicity are greater than ( $\mathrm{CI}>1$ or antagonism), equal to $(\mathrm{CI}=1$ or addition $)$ or less than $(\mathrm{CI}<1$ or synergism) the 


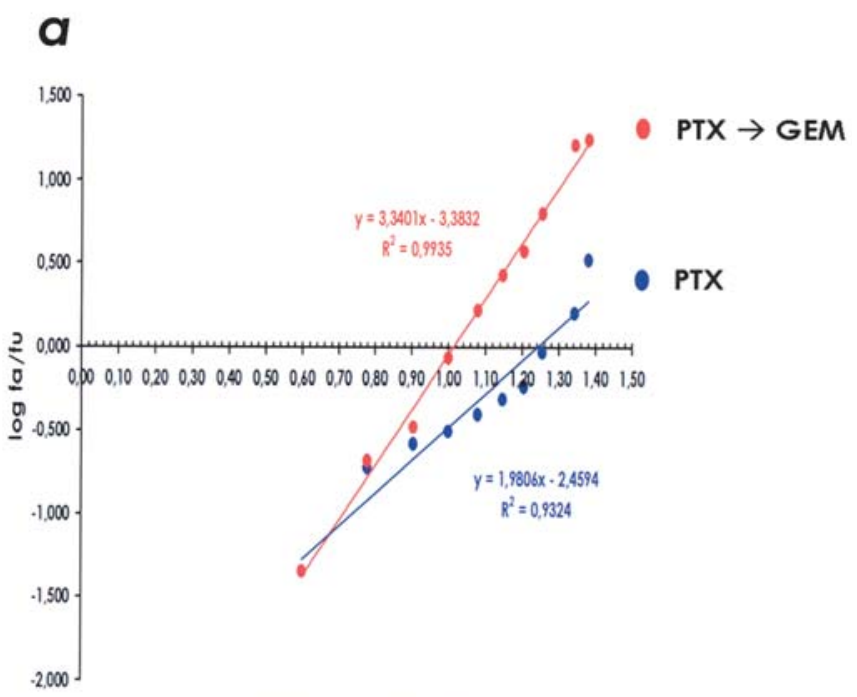

$\log$ PIX concentration (nM)

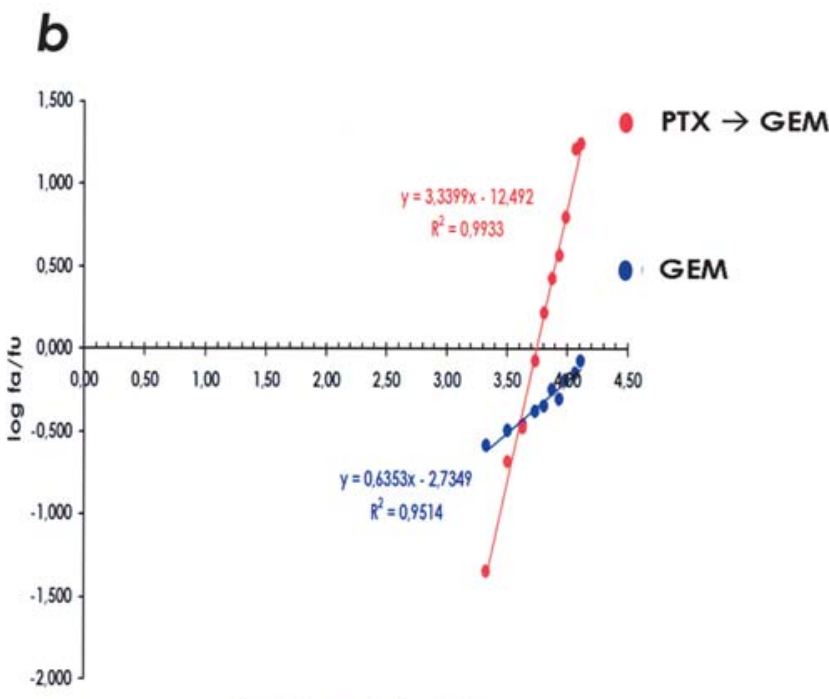

$\log$ GEM concentration ( $\mathrm{nM})$
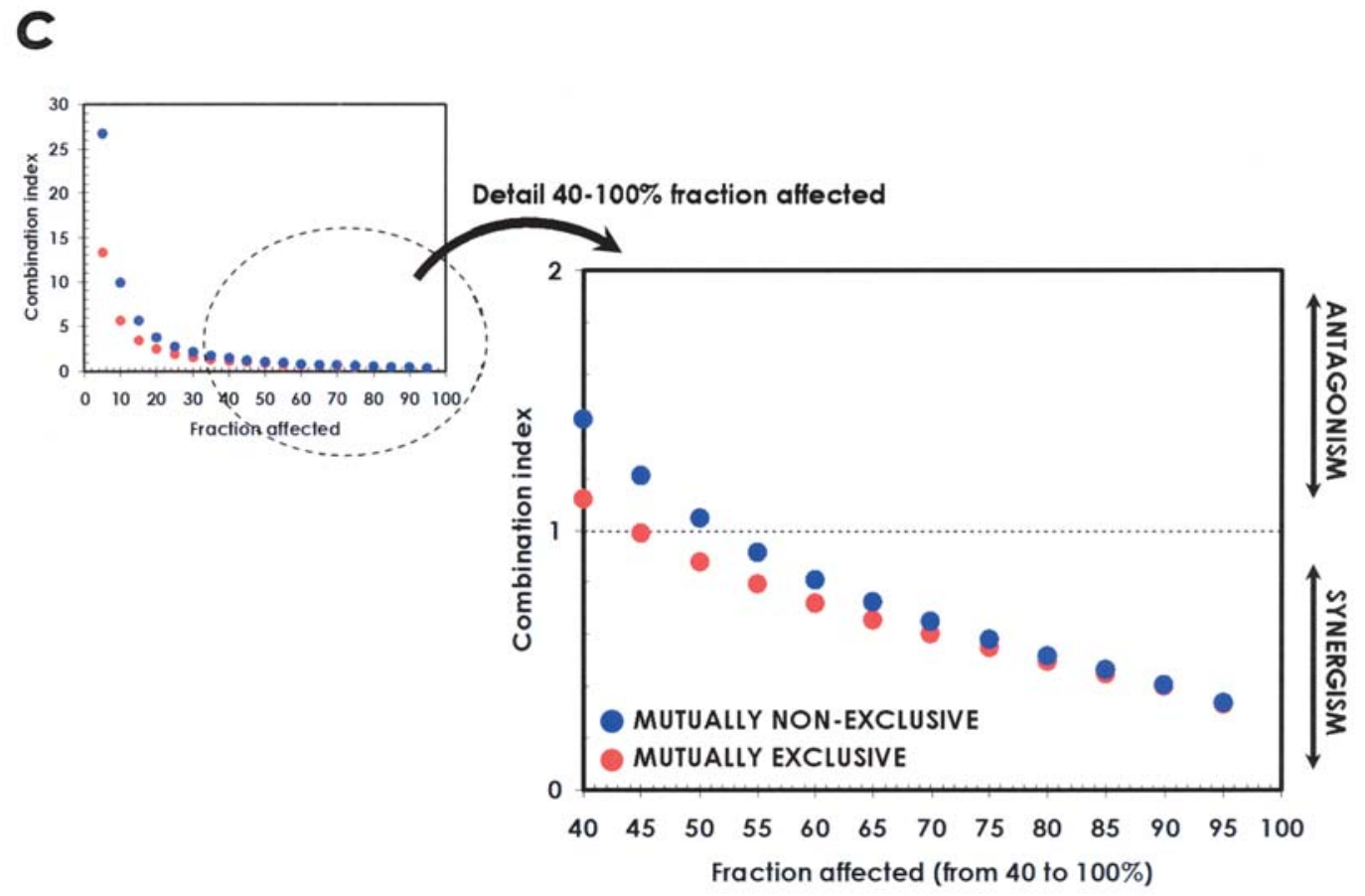

Figure 2. Synergistic effect of PTX and GEM on growth inhibition in MCF-7 breast cancer cells. (a and b) Median-effect plot. Effect of PTX, GEM or PTX $\rightarrow$ GEM at a constant ratio was measured by MTT assays as described in Materials and methods. The log values of the ratios of fraction affected to fraction unaffected $\left(\log \mathrm{f}_{\mathrm{a}} / \mathrm{f}_{\mathrm{u}}\right)$ were plotted against $\log$ values of concentrations of PTX and GEM single agents of PTX/GEM concentrations in combinations as shown in the median-effect plot. $\mathrm{IC}_{50}$ values of single drugs or the combination were determined from the $\mathrm{x}$-intercepts where $\log \left(\mathrm{f}_{\mathrm{a}} / \mathrm{f}_{\mathrm{u}}=0\right)$. $(\mathrm{c})$ Combination Index $(\mathrm{CI}) /$ effect plot. Combination index values of combination treatment were analyzed as described in Materials and methods and plotted against fractional inhibition by the combination treatment. Significant synergism (Combination Index $<0.8$ ) was indicated for the PTX $\rightarrow$ GEM combination at cell growth inhibitory effects $>50 \%$.

doses that would be required if the two agents were strictly additive. For this type of analysis and for each drug separately (i.e., PTX and GEM), we measured how the fraction affected (i.e., the fractional cell toxicity) varied with differing doses. For two drugs in combination (i.e., PTX $\rightarrow$ GEM) we varied the doses of the two agents while monitoring the fraction affected; however, the doses were varied such that a constant ratio of agent 1 (PTX) to agent 2 (GEM) was maintained. Specifically, 1.5, 2.0- and 3.0-fold serial dilutions of PTX and GEM were prepared and combined with each other from the lowest to the highest concentration while assessing the cell fraction affected (Fig. 2a and b). The combination ratio was designed to approximate the $\mathrm{IC}_{50}$ ratio of the drugs determined in preliminary experiments, so that the contribution of the effect for PTX and GEM in the mixture would be the same (i.e., equipotency ratio). Fig. 2c shows the CI plots at various effect levels (fraction affected) for the sequential combination $\mathrm{PTX} \rightarrow \mathrm{GEM}$ in MCF-7 breast cancer cells. The synergy observed with sequential PTX prior to GEM exposure for $72 \mathrm{~h}$ was apparent at levels exceeding the $50 \%$ cell kill boundary, with CI values ranging from 0.877 (moderate synergism) at the $\mathrm{IC}_{50}$ to 0.331 (strong synergism) at the $\mathrm{IC}_{95}$. 

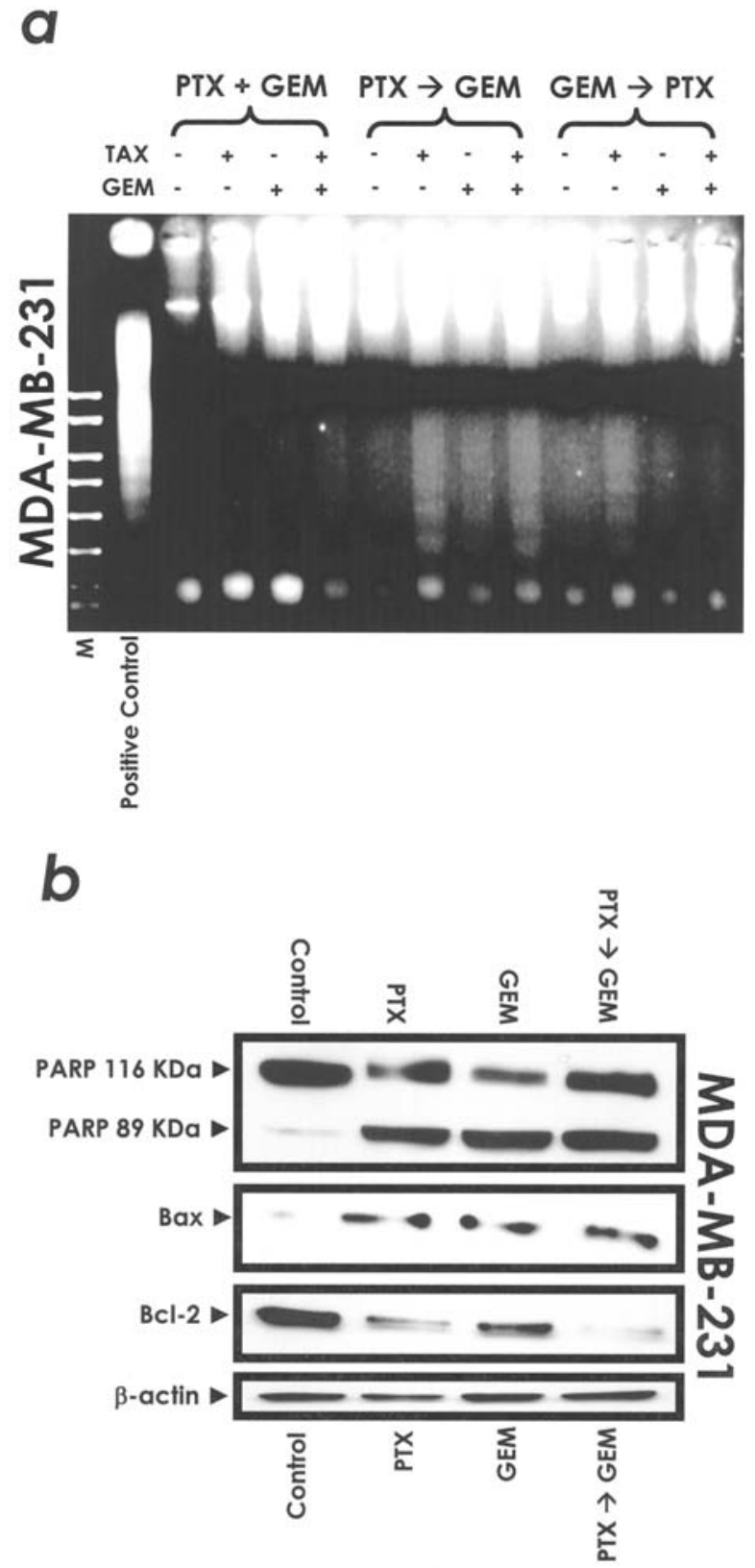

Figure 3. Assessment of apoptotic cell death. (a) DNA-laddering assay. Genomic DNA was prepared from MDA-MB-231 cells that were treated as specified. DNAs were fractioned on agarose gels, stained with ethidium bromide, and photographed. M, DNA molecular weight marker. (b) Western blot analyses for the PARP, Bax, and Bcl-2 proteins. Total whole-cell proteins were extracted from MDA-MB-231 cells treated with GEM alone with or without pre-exposure to PTX. Equal amounts of cellular protein were fractionated on a 4-12\% MOPS NuPage gel and transferred to nitrocellulose membranes, followed by immunoblotting with anti-PARP, Bax, and Bcl-2 antibodies. PARP cleavage was analyzed using an anti-PARP antibody detecting both intact PARP $(116 \mathrm{kDa})$ and the apoptotic marker PARP cleavage fragment $(85 \mathrm{kDa})$. B-actin was used as a loading control. A representative Western blot analysis is shown. Equivalent results were obtained in three independent experiments.

These findings, altogether, reveal that sequential administration of PTX followed by GEM is necessary for maximal augmentation of cytotoxicity in breast cancer cells.

Apoptosis. To gain additional insight into the molecular mechanisms underlying the synergism/antagonism occurring when combining PTX and GEM, we investigated the possible influence of the schedule treatment on PTX/GEM-induced apoptosis. Since an important hallmark of apoptotic cell death is the fragmentation of genomic DNA into integer multiples of 180-bp units, we first performed a DNA fragmentation assay (Fig. 3a). When MDA-MB-231 cells were exposed to GEM alone, essentially no clear DNA fragmentation was observed. However, on combination treatment with GEM and PTX, particularly when these cells were pre-exposed to PTX, GEM-induced DNA fragmentation was significantly increased, thus suggesting that the pre-treatment with PTX enhances GEM-induced apoptotic cell death in GEM-resistant MDAMB-231 breast cancer cells.

We then performed immunoblotting on apoptotic markers such as Poly(ADP-ribose) polymerase (PARP), Bax and Bcl-2. PARP, a nuclear enzyme involved in DNA repair and activated in response to DNA-damage, is an early target of caspases during apoptosis (22-25). The specific cleavage of this protein by caspase- 3 onto 89 - and $24-\mathrm{kDa}$ fragments is considered to be a hallmark of the apoptotic mode of cell death (22-25). $\mathrm{Bax}$ and $\mathrm{Bcl}-2$ are members of the $\mathrm{Bcl}-2$ protein family, which is involved in the apoptotic pathway (26-29). In fact, increases in the $\mathrm{Bax} / \mathrm{Bcl}-2$ ratio relate to increases in the extent of apoptotic cell death.

When PARP cleavage was evaluated using an antibody that recognizes both the intact 116-kDa (PARP p116) and the cleaved 89-kDA fragment (PARP p89), PARP was likewise cleaved as shown by the appearance of a signature 85-kDa fragment in whole cell lysates from PTX-, GEM-, and PTX $\rightarrow$ GEM-treated MDA-MB-231 cells. However, immunoblotting-based assessment of PARP cleavage did not reveal significant differences between treatment groups (PTX alone, GEM alone, or PTX $\rightarrow$ GEM sequential combination), indicating the existence of a threshold above which a rise in cell damage does not result in further PARP cleavage (Fig. 3b). Interestingly, a significantly higher $\mathrm{Bax} / \mathrm{Bcl}-2$ ratio was detected upon sequential treatment with PTX prior to GEM when compared to that obtained using single-drug treatments (Fig. 3a). Overall, the data show that the PTX $\rightarrow$ GEM sequential combination results in a significant activation of the mitochondrial damage pathway in GEM-resistant MDAMB-231 breast cancer cells.

\section{Discussion}

Although it is generally accepted that cell lines and preclinical data have limitations in their ability to accurately model the clinical picture, the use of preclinical evidence in designing chemotherapy combinations and schedules is not without value. In this regard, there is discordance between the potential antagonism between taxanes and Gemcitabine in some preclinical models and the positive clinical results obtained by the combinations of Gemcitabine and either Paclitaxel or Docetaxel. The present study demonstrates that, using in vitro experimentation, the combination of PTX and GEM can exhibit synergistic anticancer activity against breast cancer cells. Our experimental results may explain, at least in part, the good response rates that are achieved in clinical studies where the two drugs are combined in the treatment of metastatic breast cancer patients (15-18). 
Our study demonstrates that the nature of the interaction between PTX and GEM (i.e., antagonism, addition, and synergism) is schedule-dependent. We analyzed three possible schedules (i.e., PTX + GEM, GEM $\rightarrow$ PTX, and PTX $\rightarrow$ GEM), and we found that synergistic interactions are mainly observed upon the sequence of PTX prior to GEM. This synergism is consistent with the results of Kroep et al (30), who showed that treatment with PTX significantly increases the cellular content on dFdCTP (i.e., the active form of GEM), thus improving GEM efficacy. Henley et al (31) suggested that the synergism occurring when combining PTX followed by GEM, rather than related to cell cycle progression arrest, might relate to the specific activation of the $\mathrm{Bcl}-2$ apoptotic pathway. Here, we further clarify that exposure of breast cancer cells to PTX prior to GEM results in decreased expression of Bcl-2 with reciprocal increase in Bax protein. This increase in the $\mathrm{Bax} / \mathrm{Bcl}-2$ ratio can be proposed to drive the synergistic apoptotic cell death occurring in the PTX followed by GEM schedule.

In summary, through a series of in vitro assays including MTT-based cell viability assays, DNA fragmentation, and immunoblotting-based assessment of apoptotic markers, we provide evidence that antagonism can occur when breast carcinoma cells are exposed to PTX and GEM simultaneously or exposed to GEM before PTX. However, a clinically relevant synergism occurs when PTX is administered before GEM. These findings support earlier in vitro studies $(32,33)$ and, more importantly, our own clinical results, in which patients with metastatic breast cancer treated with PTX and GEM demonstrated an overall response rate of $71 \%(34,35)$. This high response rate of the PTX/GEM regimen may be, at least in part, a clinical consequence of the synergism occurring at the cellular/molecular level.

\section{Acknowledgments}

JAM is the recipient of a Basic, Clinical and Translational Research Award (BCTR0600894) from the Susan G. Komen Breast Cancer Foundation (Texas, USA). This study was also supported by the Instituto de Salud Carlos III (Ministerio de Sanidad y Consumo, Fondo de Investigación Sanitaria -FIS-, Spain, grants CP05-00090 and PI06-0778 to JAM, and grant RD06-0020-0028 to JAM, JB, RdL, and RC).

\section{References}

1. Wani MC, Taylor HL, Wall ME, Coggon P and McPhail AT: Plant antitumor agents. VI. The isolation and structure of taxol, a novel antileukemic and antitumor agent from Taxus brevifolia. J Am Chem Soc 93: 2325-2327, 1971.

2. Blagosklonny MV and Fojo T: Molecular effects of paclitaxel: myths and reality (a critical review). Int J Cancer 83: 151-156, 1999.

3. Dumontet $\mathrm{C}$ and Sikic BI: Mechanisms of action of and resistance to antitubulin agents: microtubule dynamics, drug transport, and cell death. J Clin Oncol 17: 1061-1070, 1999.

4. Sawaki M, Ito Y, Hashimoto D, Mizunuma N, Takahashi S, Horikoshi N, Tada K, Kasumi F, Akiyama F, Sakamoto G, Imai T, Nakao A and Hatake K: Paclitaxel administered weekly in patients with docetaxel-resistant metastatic breast cancer: a single-center study. Tumori 90: 36-39, 2004.

5. Baltali E, Altundag K, Ozisik Y, Guler N and Tekuzman G: Weekly paclitaxel in pretreated metastatic breast cancer: retrospective analysis of 52 patients. Tohoku J Exp Med 203: 205-210, 2004.
6. Ranson $\mathrm{M}$ and Thatcher N: Paclitaxel: a hope for advanced nonsmall cell lung cancer? Expert Opin Investig Drugs 8: 837-848, 1999.

7. Thomas $\mathrm{H}$ and Rosenberg P: Role of weekly paclitaxel in the treatment of advanced ovarian cancer. Crit Rev Oncol Hematol 44 (suppl): S43-S51, 2002.

8. Hui YF and Reitz J: Gemcitabine: a cytidine analogue active against solid tumors. Am J Health Syst Pharm 54: 162-170, 1997.

9. Plunkett W, Huang P, Searcy CE and Gandhi V: Gemcitabine: preclinical pharmacology and mechanisms of action. Semin Oncol 23 (suppl 10): 3-15, 1996.

10. Huang P, Chubb S, Hertel LW, Grindey GB and Plunkett W: Action of 2',2'-difluorodeoxycytidine on DNA synthesis. Cancer Res 51: 6110-6117, 1991 .

11. Schmid P, Akrivakis K, Flath B, Grosse Y, Sezer O, Mergenthaler HG and Possinger K: Phase II trial of gemcitabine as prolonged infusion in metastatic breast cancer. Anticancer Drugs 10: 625-631, 1999.

12. Blackstein M, Vogel CL, Ambinder R, Cowan J, Iglesias J and Melemed A: Gemcitabine as first-line therapy in patients with metastatic breast cancer: a phase II trial. Oncology 62: 2-8, 2002.

13. Spielmann M, Llombart-Cussac A, Kalla S, Espie M, Namer M, Ferrero JM, Dieras V, Fumoleau P, Cuvier C, Perrocheau G, Ponzio A, Kayitalire L and Pouillart P: Single-agent gemcitabine is active in previously treated metastatic breast cancer. Oncology 60: 303-307, 2001.

14. Brodowicz T, Kostler WJ, Moslinger R, Tomek S, Vaclavik I, Herscovici V, Wiltschke C, Steger GG, Wein W, Seifert M, Kubista E and Zielinski CC: Single-agent gemcitabine as second- and third-line treatment in metastatic breast cancer. Breast 9: 338-342, 2000.

15. Colomer R: What is the best schedule for administration of gemcitabine-taxane? Cancer Treat Rev 31 (suppl 4): S23-S28, 2005 .

16. Allouache D, Gawande SR, Tubiana-Hulin M, Tubiana-Mathieu N, Piperno-Neumann S, Mefti F, Bozec L and Genot JY: First-line therapy with gemcitabine and paclitaxel in locally, recurrent or metastatic breast cancer: a phase II study. BMC Cancer 5: 151, 2005

17. Yardley DA: Gemcitabine plus paclitaxel in breast cancer. Semin Oncol 32 (suppl 6): S14-S21, 2005.

18. Tomao S, Romiti A, Tomao F, Di Seri M, Caprio G, Spinelli GP, Terzoli E and Frati L: A phase II trial of a biweekly combination of paclitaxel and gemcitabine in metastatic breast cancer. BMC Cancer 6: 137, 2006.

19. Mosmann T: Rapid colorimetric assay for cellular growth and survival: application to proliferation and cytotoxicity assays. J Immunol Methods 65: 55-63, 1983.

20. Berenbaum MC: What is synergy? Pharmacol Rev 41: 93-141, 1989.

21. Chou T-C, Motzer RJ, Tong T and Bosl GJ: Computerized quantitation of synergism and antagonism of paclitaxel, topotecan, and cisplatin against human teratocarcinoma cell growth: a rational approach to clinical protocol design. J Natl Cancer Inst 86: 1517-1524, 1994.

22. Kaufmann SH, Desnoyers S, Ottaviano Y, Davidson NE and Poirier GG: Specific proteolytic cleavage of poly(ADP-ribose) polymerase: an early marker of chemotherapy-induced apoptosis. Cancer Res 53: 3976-3985, 1993.

23. Lazebnik YA, Kaufmann SH, Desnoyers S, Poirier GG and Earnshaw WC: Cleavage of poly(ADP-ribose) polymerase by a proteinase with properties like ICE. Nature 371: 346-357, 1994.

24. Oliver FJ, de la Rubia G, Rolli V, Ruiz-Ruiz MC, de Murcia G and Murcia JM: Importance of poly(ADP-ribose) polymerase and its cleavage in apoptosis. Lesson from an uncleavable mutant. J Biol Chem 273: 33533-33539, 1998.

25. Shah GM, Kaufmann SH and Poirier GG: Detection of poly(ADP-ribose) polymerase and its apoptosis-specific fragment by a nonisotopic activity-Western blot technique. Anal Biochem 232: 251-254, 1995.

26. Cory S, Huang DC and Adams JM: The Bcl-2 family: roles in cell survival and oncogenesis. Oncogene 22: 8590-8607, 2003.

27. Chan SL and Yu VC: Proteins of the bcl-2 family in apoptosis signalling: from mechanistic insights to therapeutic opportunities. Clin Exp Pharmacol Physiol 31: 119-128, 2004.

28. Cory S and Adams JM: Killing cancer cells by flipping the Bcl-2/ Bax switch. Cancer Cell 8: 5-6, 2005.

29. Adams JM and Cory S: The Bcl-2 apoptotic switch in cancer development and therapy. Oncogene 26: 1324-1337, 2007. 
30. Kroep JR, Giaccone G, Voorn DA, Smit EF, Beijnen JH, Rosing H, van Moorsel CJ, van Groeningen CJ, Postmus PE, Pinedo HM and Peters GJ: Gemcitabine and paclitaxel: pharmacokinetic and pharmacodynamic interactions in patients with non-small-cell lung cancer. J Clin Oncol 17: 2190-2197, 1999.

31. Henley D, Isbill M, Fernando R, Foster JS and Wimalasena J: Paclitaxel induced apoptosis in breast cancer cells requires cell cycle transit but not Cdc2 activity. Cancer Chemother Pharmacol 59: 235-249, 2007.

32. Zupi G, Scarsella M, D'Angelo C, Biroccio A, Paoletti G, Lopez $\mathrm{M}$ and Leonetti C: Potentiation of the antitumoral activity of gemcitabine and paclitaxel in combination on human breast cancer cells. Cancer Biol Ther 4: 866-871, 2005.
33. Sui M, Xiong X, Kraft AS and Fan W: Combination of gemcitabine antagonizes antitumor activity of paclitaxel through prevention of mitotic arrest and apoptosis. Cancer Biol Ther 5: 1015-1021, 2006.

34. Colomer R, Llombart-Cussac A, Lluch A, Barnadas A, Ojeda B, Caranana V, Fernandez Y, Garcia-Conde J, Alonso S, Montero S, Hornedo $\mathrm{J}$ and Guillem V: Biweekly paclitaxel plus gemcitabine in advanced breast cancer: phase II trial and predictive value of HER2 extracellular domain. Ann Oncol 15: 201-206, 2004.

35. Colomer R: Gemcitabine and paclitaxel in metastatic breast cancer: a review. Oncology 18 (suppl 12): 8-12, 2004. 